\title{
Investigations on Millimeter Wave (mmW) Antenna for 5G Technology: Design Considerations and Applications
}

\author{
Sohni Singh*, Manvinder Sharma, Pankaj Palta and Anuj Kumar Gupta \\ Department of Computer Science and Engineering \\ Chandigarh College of Engineering, Landran \\ Email Id: *sohnibagga5@gmail.com
}

\begin{abstract}
The millimeter wave technology has made its way to the 5G technology as the system of 5G requires larger bandwidth, higher frequency and system capacity. In order to achieve these parameters, the millimeter wave antenna research becomes necessary. The current wireless technologies require huge bandwidth which makes the spectrum of millimeter wave a potential candidate. Microstrip antennas have always been in an increasing demand due to their exceptional performance in the applications of wireless communication. The advantages of microstrip patch antenna led to its popularity among the researchers. The technologies such as MIMO, CMOS and beam forming are used with millimeter wave antenna for improving the mobile phone performance. There are various designs of microstrip patch antenna related to 5G technology and applications in the millimeter wave band which are discussed in the paper.
\end{abstract}

Keywords - Microstrip Patch Antenna, 5G technology, Millimeter Wave, Wireless Applications, Bandwidth;)

\section{INTRODUCTION}

$5 \mathrm{G}$ stands for fifth generation in telecommunication. In cellular networks, $5 \mathrm{G}$ technology is a standard which has been deployed by various companies of cellular phone in 2019 worldwide. 5G technology is a successor to the networks of $4 \mathrm{G}$ through which the connectivity to most of the current cellphones is provided. There is division of the service area in 5G cellular networks into small cells. These cells are the geographical areas inside the cellular network. A single cell contains large number of $5 \mathrm{G}$ wireless devices which are connected to the cellular network and internet by radio waves via antenna present in the cell. This new network has various advantages such as larger bandwidth and higher data rates [1-2]. Because of the larger bandwidth, the new networks can be used as internet service providers to desktop computers and laptops. The new applications in M2M and IoT areas would also be possible. The NR (New Radio) air interface for $5 \mathrm{G}$ is divided into frequency bands. First one is FR1 which has the frequency range below 6 $\mathrm{GHz}$ and other is FR2 for millimeter wave frequency. Each frequency band has different capabilities. The maximum bandwidth of the channel for FR1 is $100 \mathrm{MHz}$ because the frequency range is highly crowded which further lacks the continuous spectrum [3]. The channel bandwidth for FR2 is $50 \mathrm{MHz}-400 \mathrm{MHz}$ high speed data transfer is supported by higher frequency. Various applications of 5G technology include automobiles, public safety, fixed wireless and broadcast applications as the wireless video transmission would be possible. The services of the wireless communication are increasing in demand day by day due and have possessed a great challenge to the current wireless communication system due to lack of bandwidth requirement [4-5]. The millimeter wave technology has made its way to the $5 \mathrm{G}$ technology as the system of $5 \mathrm{G}$ requires larger bandwidth, higher frequency and system capacity. In order to achieve these parameters, the millimeter wave antenna research becomes necessary. The large transmission gain and high bandwidth are the two main utmost important factors of millimeter wave antenna
[6]. The frequency of $28 \mathrm{GHz}$ and $72 \mathrm{GHz}$ are introduced in the MMB (millimeter-wave mobile broadband) system. In comparison to the microwave, the propagation loss and the penetration loss of millimeter wave is much less which relatively leads to long links and higher antenna gain. The capacity and the spectrum requirements are the prominent factors owing to increased data traffic the current wireless communication system [7]. The 5G mobile network can use the millimeter wave band of high bandwidth to provide various communication services such as HDTV (high definition television) and UHDV (ultra-high definition video). The electronic products used in the millimeter wave band such as CMOS (Complementary metal-oxide Semiconductor) and RF (Radio Frequency) integrated circuits have been in rapid progress. There are many factors on which the applications dependent on the $5 \mathrm{G}$ operations are enabled [8-9]. These factors include spectrum selection, antenna technology, digital signal processing, and transceiver integration along with propagation characteristics. The current wireless technologies require huge bandwidth which makes the spectrum of millimeter wave a potential candidate of such technologies. Therefore, a significant amount of work is dine in collecting the substantial knowledge about the millimeter wave spectrum as the $5 \mathrm{G}$ technology is evolving at a fast pace in industrial and commercial applications. In wireless systems, antenna is the most important component as it affects the sensitivity of the receiver, transceiver designs, link budget and the schemes made in the choice of digital modulation [10]. There are improved characteristics in the design of millimeter wave antenna such as size of the antenna, bandwidth, high data rate, traffic demand and the antenna gain. The basic ground for the $5 \mathrm{G}$ technology is provided by the radio frequency at millimeter wave. The spectrum of the millimeter wave is $30 \mathrm{GHz}-300 \mathrm{GHz}$ as shown in figure 1 . The spectrum required for the $5 \mathrm{G}$ application is $20 \mathrm{GHz}-$ $90 \mathrm{GHz}$. The antenna for the $5 \mathrm{G}$ technology is designed at various frequencies of $28 \mathrm{GHz}, 38 \mathrm{GHz}$ and $72 \mathrm{GHz}$. They have the bandwidths of $500 \mathrm{MHz}, 1 \mathrm{GHz}$ and $2 \mathrm{GHz}$. These bandwidths are suitable for low latency system and high 
data rates. Such type of antenna design can be used in the $5 \mathrm{G}$ cellular applications because of their high directivity and sensitivity to the obstacles having narrow width.

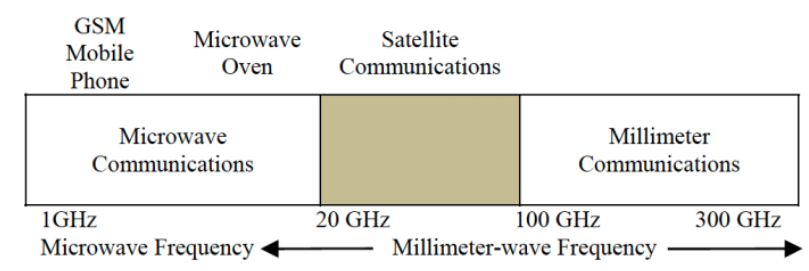

Fig. 1.Millimeter wave spectrum

\section{MILLIMETER WAVE ANTENNA FOR 5G TECHNOLOGY}

As the demand of the mobile traffic is increasing significantly, there is prominent shortage of the spectrum and capacity requirements. $5 \mathrm{G}$ wireless networks require large bandwidth. Therefore, the millimeter wave band having huge bandwidth of $30 \mathrm{GHz}-300 \mathrm{GHz}$ prove to be an integral part of the $5 \mathrm{G}$ wireless system. The current research is mostly focused on $28 \mathrm{GHz}, 38 \mathrm{GHz}$ and 60 $\mathrm{GHz}$ frequency. Due to the rapid and fast progress in CMOS (Complementary Metal Oxide Semiconductor) and RF (Radio Frequency) integrated circuits, the electronic components and devices can easily compliment the millimeter wave communication [11-12]. There are various standards defined for WLAN and WPAN such as IEEE 802.1, ECMA-387 which helps in extending the millimeter wave band network in cellular system. There are various challenges faced by the millimeter wave communication in the physical layer and the routing layer because it varies significantly with the current microwave band communication. This leads to the great impact on $5 \mathrm{G}$ wireless communication system [13]. New insights and thoughts in the protocols and architecture of the millimeter wave communication is required in terms of directivity, propagation loss and sensitivity caused by the mobility of the communication.

\section{A. $5 G$ Related Millimeter Wave (mmW) Microstrip Patch Antenna}

To develop a mobile network in 5G, the designing of a suitable antenna become very critical. The proper measurement of various antenna parameters is required to check on the suitability in 5G network and technology. The technologies such as MIMO, CMOS and beam forming are used with millimeter wave antenna for improving the mobile phone performance. There are various designs of microstrip patch antenna related to 5G technology. An antenna for $5 \mathrm{G}$ technology with circular polarization was designed which focused on the miniaturization of patch and enhancing the beam width. Consideration of various parameters is necessary to design an antenna for $5 \mathrm{G}$ cellular network which include bandwidth, antenna size, operating frequency, manufacturing cost and polarization. The size of the antenna is reduced by introducing folded type antenna of circular shape. The antenna beam width is enhanced by surrounding the patch antenna with dielectric substrate and adding the metallic block at the rear side of the antenna [14]. 5G directional antenna was designed using the technology of millimeter wave spectrum to face the challenges of rapid increase in the growth of mobile users. This required large bandwidth for efficient communication [15]. 5G wideband rectangular shaped antenna is used at $6 \mathrm{GHz}$ frequency which satisfied the requirements of $5 \mathrm{G}$ technology. The design technology of far field radiation pattern is used in the antenna which significantly analyzed the environmental parameters of atmospheric absorption [16]. 5G directional antenna is designed at the operating frequency of $28 \mathrm{GHz}$ and $38 \mathrm{GHz}$ in the mobile communication of millimeter wave spectrum. This design followed some effective approaches such as impedance matching optimization, multiple resonance and increasing the substrate thickness which results in the reduced substrate permittivity. The substrate of high dielectric constant is used which reduced the radiation losses [17]. A CPW fed design microstrip patch antenna is designed for $5 \mathrm{G}$ technology with operating frequency of $8.4 \mathrm{GHz}$ WSN, WLAN, Hyper LAN and Wi-Fi technology. These designs use fractal technology for multiple band spectrum operation and better impedance matching [18]. 5G array patch antenna is designed at the operating frequency of $18 \mathrm{GHz}-28 \mathrm{GHz}$. The wide area is covered using the modified antenna array design. The radiation pattern of Omni direction is used with this design to avoid the traffic rate. High gain is achieved by placing the identical sub arrays with coaxial probe feed [19]. 5G wideband patch antenna is designed at the operating frequency of $6 \mathrm{GHz}$ using MIMO (Multiple input Multiple output) technology which increases the gain and quality of service [20]. Table 1 shows the complete comparison of antenna designs used at $5 \mathrm{G}$ cellular network and communication technology.

TABLE 1. COMPARISON OF ANTENNAS FOR 5G.

\begin{tabular}{|c|c|c|c|}
\hline S.No & Type of Antenna & Technology & $\begin{array}{l}\text { Features/ } \\
\text { Advantages }\end{array}$ \\
\hline 1 & $\begin{array}{l}\text { Circular Polarized } \\
\text { Antenna }\end{array}$ & $\begin{array}{l}\text { Technique of } \\
\text { miniaturization }\end{array}$ & $\begin{array}{ll}\text { Beam } & \text { width } \\
\text { enhancement } & \\
\end{array}$ \\
\hline 2 & $\begin{array}{l}\text { Directional } \\
\text { Antenna }\end{array}$ & $\begin{array}{l}\text { Millimmeter wave } \\
\text { spectrum }\end{array}$ & $\begin{array}{l}\text { Bandwidth } \\
\text { improvement }\end{array}$ \\
\hline 3 & $\begin{array}{l}\text { 5G Wideband } \\
\text { Antenna }\end{array}$ & $\begin{array}{l}\text { Design of far field } \\
\text { radiation pattern }\end{array}$ & $\begin{array}{ll}\text { Analysis } & \text { of } \\
\text { environmental } & \\
\text { parameters } & \\
\end{array}$ \\
\hline 4 & $\begin{array}{l}\text { 5G Directional } \\
\text { Antenna }\end{array}$ & $\begin{array}{l}\text { Millimeter wave } \\
\text { spectrum }\end{array}$ & $\begin{array}{l}\text { Multiple resonance } \\
\text { and impedance } \\
\text { matching }\end{array}$ \\
\hline 5 & $\begin{array}{lr}\text { Microstrip } & \text { Patch } \\
\text { antenna } & \text { with } \\
\text { CPW feed design }\end{array}$ & $\begin{array}{l}\text { Fractal } \\
\text { Technology }\end{array}$ & $\begin{array}{ll}\text { Multiple band } \\
\text { spectrum and good } \\
\text { impedance } \\
\text { matching }\end{array}$ \\
\hline 6 & $\begin{array}{l}\text { 5G Array Patch } \\
\text { Antenna }\end{array}$ & $\begin{array}{l}\text { MIMO } \\
\text { Technology }\end{array}$ & $\begin{array}{l}\text { Improved space } \\
\text { coverage }\end{array}$ \\
\hline 7 & $\begin{array}{l}5 \mathrm{G} \text { wideband } \\
\text { patch Antenna }\end{array}$ & $\begin{array}{l}\text { MIMO } \\
\text { Technology }\end{array}$ & Gain improvement \\
\hline
\end{tabular}

\section{MILLIMEMETER WAVE (MMW) ANTENNA DESIGN CONSIDERATIONS}

The design of the communication system in $5 \mathrm{G}$ need to support high data rates and high speed with maximum frequency band coverage. The spectrum allocation and coverage depend on various applications such as smart buildings and sensor networks. High gain of the antenna 
is one of the most essential and desirable requirements to balance the path loss created at millimeter wave frequency and system cost reduction. The other desirable properties of designing such an antenna include high efficiency, compact size and technology of multi-antenna. The radiation patterns should be stable over the entire frequency band. The antenna should be low profile and can be easily integrated with various electronic devices. Higher levels of received signals are desirable which can be achieved by increased antenna efficiency and gain [21]. The technology of multi-antenna increases the quality of received signal by maintaining the link through the production of high gain beams. The high frequency antenna design is achieved by miniaturizing the front end of RF and on-chip system integration without comprising on bandwidth, radiation efficiency and gain. The capacity of the system design can be increased by using the techniques of multiplexing that relies on baseband signal processing. The feeding structure is also one of the significant design considerations in the antenna array design at millimeter wave frequency band. Radiation and conduction losses are experienced by traditional feeding techniques such as coplanar waveguides and microstrip lines at millimeter wave frequencies. This restricts the gain reduces the efficiency of antenna arrays [22]. To design the millimeter wave antenna at high gain, waveguide structure is preferred over the microstrip line because of lower losses. This kind of design is not suitable for production at large scale due to bulky volume and huge production costs. SIW (Substrate Integrated Waveguide) is an alternate option for applications in millimeter wave communication as it has the characteristic of low fabrication cost, low loss and planer structure [23].

\section{APPLICATIONS OF MILLIMETER WAVE BAND IN WIRELESS COMMUNICATION}

The investigations on millimeter wave technology has been explored intensively in 1965 on radio communication, atmospheric sensing, radars and satellite imagery [24]. The low-cost transceiver design is made possible with the millimeter wave technology. These transceivers have components of small size and which are specially for wireless communication having high speed and short range with applications of high resolution and accuracy. There are three frequency bands in the millimeter wave spectrum which are V-band, E-band and $\mathrm{W}$-band. The applications used in all the three bands are discussed.

\section{A. V-Band: Wireless Communications with High- Speed and Short-Range}

$\mathrm{V}$-band is the $60 \mathrm{GHz}$ band that is unlicensed allocated by FCC (Federal Communication Commission) in which the spectral band of $5 \mathrm{GHz}$ is utilized by the researchers. The advantages include interference immunity, frequency reuse and high security [25-27]. The losses in the atmospheric oxygen is very high in the V-band millimeter wave spectrum due to which the attractive resources in the wireless industry are exploited which include radar sensors of high resolution with short distance and indoor communications of high speed. Therefore, short range communication is suitable for atmospheric losses of 10-15
$\mathrm{dB} / \mathrm{km}$. Some of the V-band applications include video transmission at high definition, wireless ethernet, high speed file transfer and short-range communications.

\section{B. E-Band: Radar Detectors}

The sensors and radars are required for traffic detail monitoring very precisely around the vehicle. The system of driver assistance is one of the major applications which uses the most important technology of millimeter wave radar. The vehicle radar detectors have two frequency bands of $24 \mathrm{GHz}$ and $77 \mathrm{GHz}$. A critical role is played by the size of the sensor related to the antenna as all the sensors are integrated in the vehicle. The antenna size is smaller for larger frequencies which in return require large apertures. The absolute bandwidth of $4 \mathrm{GHz}$ is required by the radars of short range to attain high resolution [28-29]. The high distance and long-range abilities and operations are ensured by combining high bandwidth and high transmit power. $77 \mathrm{GHz}$ frequency band allows this combination.

\section{W-band: Radiometric Imaging Systems in Millimeter Wave}

The recent and challenging technology in the domain of wireless communication is imagery. The $\mathrm{W}$-band has the frequency band of $85 \mathrm{GHz}-94 \mathrm{GHz}$ [30-31]. The most important application of W-band is indoor and outdoor imaging. The active imaging radars have high resolution and are low range and therefore more suitable than infrared and optical sensors. A fixed atmospheric attenuation is allocated in the wavelength of $3 \mathrm{~mm}$ and $9 \mathrm{~mm}$. so, the movement through fog, dust, rain and smoke is easily allowed while avoiding the obstacles. The useful information of aircraft landing can be provided by the imaging radars so that the dependence on the instrument present at the ground plane is reduced. The transparent dielectrics are present in the W-band spectrum of millimeter wave. So, a millimeter wave sensor can be used to detect the weapons while scanning a group of people. Surveillance and security confirm their needs of millimeter wave imaging. The early cancer detection in the diagnostic medicine field can also be done by millimeter wave imagery [32]. As compared to X-Ray imagery, the interaction of the target with the microwave radiation is based on the dielectric rather than on the density.

\section{v. CONCLUSION}

The millimeter wave technology has made its way to the $5 \mathrm{G}$ technology as the system of $5 \mathrm{G}$ requires larger bandwidth, higher frequency and system capacity. In order to achieve these parameters, the millimeter wave antenna research becomes necessary. The current wireless technologies require huge bandwidth which makes the spectrum of millimeter wave a potential candidate. The millimeter wave technology has made its way to the $5 \mathrm{G}$ technology as the system of $5 \mathrm{G}$ requires larger bandwidth, higher frequency and system capacity. In order to achieve these parameters, the millimeter wave antenna research becomes necessary. There are improved characteristics in the design of millimeter wave antenna such as size of the 
antenna, bandwidth, high data rate, traffic demand and the antenna gain. The basic ground for the $5 \mathrm{G}$ technology is provided by the radio frequency at millimeter wave. To develop a mobile network in $5 \mathrm{G}$, the designing of a suitable antenna become very critical. The proper measurement of various antenna parameters is required to check on the suitability in $5 \mathrm{G}$ network and technology. The complete comparison of antenna designs used at $5 \mathrm{G}$ cellular network and communication technology is discussed. The design considerations of the millimeter wave band antenna and the applications used in all the three bands of millimeter wave band in wireless communication is discussed in detai

\section{REFERENCES}

[1] David Alvarez Outerelo: Ana Vazwuez Aleios: Manuel GarciaSanchez; Maria Vera Isasa, "Microstrip Antenna for 5GBroadband Communication: Overview of Design Issues," in 2015IEEEinternational Symposium on antennas and Propagation \&USNC/URSI National Radio Science Meeting, 2015, pp. 24432444.

[2] Waleed Ahmad. Wasif Tanveer Khan. "Small form factor dualband (28/38 GHz) PIFA antenna for 5G applications." In 2017IEEE MTT-S International Conference on micromaves forIntelligent Mobility (ICMIM), 2017, pp. 21-24.

[3] Sharma. Manvinder. and Anui Kumar Gupta. "An Algorithm for Target Detection, Identification, Tracking and Estimation of Motion for Passive Homing Missile Autopilot Guidance." In Mobile Radio Communications and 5G Networks, pp. 57-71. Springer, Singapore, 2020.

[4] Mi. Li. K.-M. Luk. " Low-Cost Wideband Micro strip AntennaArray for 60-GHz Applications". IEEE Transactions on Antennasand Propagation, vol. 62, no. 6, pp. 3012-3018, June 2014.

[5] Elkashlan, M., Duong, T. O.. \& Chen, H.-H. (2014). Millimeterwavecommunications for 5G: Fundamentals: Part I [GuestEditorial]. IEEE Communications Magazine, 52(9), 52-54.

[6] Elkashlan, M., Duong, T. O., \& Chen, H.-H. (2015). Millimeterwavecommunications for 5G-Part 2: Applications. IEEECommunications Magazine, 53(1), 166-167.

[7] Doan, C. H., Emami, S., Sobel, D. A., Nikneiad, A. M., \&Brodersen.R.W. (2004).Design considerations for 60GHzCMOSradios. IEEE Communications Magazine, 42(12), 132-140.

[8] Gutierrez, F., Agarwal, S., Parrish, K., \& Rappaport, T. S.(2009). On-chip integrated antenna structures in CMOS for $60 \mathrm{GHz}$ WPAN systems. IEEE Journal on Selected Areas inCommunications, 27(8), 1367-1378.

[9] Rappaport, T. S., Murdock, J. N., \& Gutierrez, F. (2011). Stateof the art in $60-\mathrm{GHz}$ integrated circuits and systems for wirelesscommunications. Proceedings of the IEEE, 99(8), 1390-1436.

[10] Aiorloo, H., \& Manzuri-Shalmani, M. T. (2013). Modelingbeacon period length of the UWB and $60-\mathrm{GHz}$ mmWaveWPANs based on ECMA-368 and ECMA-387 standards. IEEETransactions on Mobile Computing, 12(6), 1201-1213.

[11] Zhang, Jing, Xiaohu Ge, Oiang Li, Mohsen Guizani, and Yanxia Zhang. "5G millimeter-wave antenna arrav: Design and challenges." IEEE Wireless communications 24, no. 2 (2016): 106-112.

[12] El Shorbagy. Menna. Raed M. Shubair. Mohamed I. AlHairi, and Nazih Khaddai Mallat. "On the design of millimetre-wave antennas for 5G." In 2016 16th Mediterranean Microwave Symposium (MMS), pp. 1-4. IEEE, 2016

[13] Hong. Wonbin. Kwang-Hvun Baek. and Seungtae Ko. "Millimeter-wave 5G antennas for smartphones: Overview and experimental demonstration." IEEE Transactions on Antennas and Propagation 65, no. 12 (2017): 6250-6261.

[14] Mak, Ka Ming, et al. "Circularly polarized patch antenna for future5G mobile phones" IEEE Access 2 (2014): 15211529.

[15] Ankita P. Manekar, Dr. S. W. Varade. IJARCCE ISSN (Online)2278-1021 ISSN (Print) 23195940 (2016. June). "Design andSimulation of Directional Antenna for Millimeter Wave MobileCommunication". International Journal of Advanced Research inComputer and Communication Engineering Vol. 5, Issue 6.

[16] MHD Amen Summakieh. Mastaneh Mokavef . (2016). "Single Wideband Microstrip Patch Antenna for 5G WirelessCommunication Applications". In Journal of Electrical andElectronics Engineering (IJR DO) Volume1, Issue-4, Paper-2.

[17] Sharma, Manvinder, Sohni Singh, DishantKhosla SumeetGoyal, and Anuj Gupta. "Waveguide Diplexer: Design and Analysis for 5G Communication." In 2018 Fifth International Conference on Parallel, Distributed and Grid Computing (PDGC), pp. 586-590. IEEE, 2018.

[18] Mohan, Gaikwad Pooia, and Mrs SR Chougale. "CPW FeedMicrostrip Patch Antenna D esign for Future 5G Communication."

[19] Atima Agarwal, Sweta Agarwal, September-October 2016)."Simulation and Analysis of 5G Mobile Phones Antenna",(International Journal of Electronics and CommunicationEngineering and Technology (IJECET) Volume 7, Issue 5, pp. 07-12, Article ID: IJECET 0705 002, ISSN Print: 0976-6464 andISSN Online: 0976-6472

[20] Chong Ming Sam, Mastanesh Mokavef, (2016, Julv). "AWideband Slotted Microstrip Patch Antenna for Future $5 \mathrm{G}$ ". EPHInternationalJournal Of Science And Engineering, ISSN:2454-2016, Vol.2,Issue:7.

[21] H. Aliakbari, A. Abdipour, R. Mirzavand, A. Costanzo, and P. Mousavi,"A single feed dual-band circularly polarized millimeter-wave antennafor $5 \mathrm{~g}$ communication." in 2016 10th European Conference on Antennasand Propagation (EuCAP), pp. 1-5.

[22] K. M. Morshed, K. P. Esselle, and M. Heimlich, "Dielectric loaded planar inverted-f antenna for millimeter-wave 5g hand held devices."in 2016 10th European Conference on Antennas and Propagation(EuCAP), pp. 1-3.

[23] Matin. Mohammad A. "Review on millimeter wave antennas-potential candidate for $5 \mathrm{G}$ enabled applications." Advanced Electromagnetics 5, no. 3 (2016): 98-105.

[24] Singh. Sohni. Sumeet Goval. Manvinder Sharma. and Rahul Kakkar. "WAVEGUIDE DIPLEXER DESIGN AND IMPLEMENTATION IN COMMUNICATION SYSTEMS."

[25] M. J. Jeong, N. Hussain, J. W. Park, S. G. Park, S. Y. Rhee.and N. Kim. "Millimeter-wave microstrip patch antennausing a vertically coupled split ring metal plate for gainenhancement,"Microw. Opt. Technol. Lett., Vol. 61, no. 10,pp. 2360-2365, 2019.

[26] Sharma, Manvinder, and Harjinder Singh. "SIW based Leaky wave antenna with Semi C-shaped slots and its Modeling, Design and parametric considerations for different materials of Dielectric." In 2018 Fifth International Conference on Parallel, Distributed and Grid Computing (PDGC), pp. 252-258. IEEE, 2018.

[27] L. Lu. X. Zhang. R. Funada. C. S. Sum. and H. Harada."Selection ofmodulation and coding schemes of single carrierPHY for 802.11 admulti-gigabit mmWave WLAN systems,"in 2011 IEEE Symposiumon Computers and Communications(ISCC), June 2011, pp. 348-352.

[28] Y. Beierano, and R. Bhatia, "Mifi: A framework for fairnessand $\mathrm{OoS}$ assurance in current IEEE 802.11 networks withmultiple access points." IEEE Trans. Network., Vol. 14, no.4, pp. 849-862, Aug. 2006.

[29] Kaur, SanamPreet, and Manvinder Sharma. "Radially optimized zone-divided energy-aware wireless sensor 
CGC International Journal of Contemporary Technology and Research

CGCFIJCTR ISSN: 2582-0486 (online) Vol.-3, Issue-1 DOI: 10.46860/cgcijctr.2020.12.26.149

networks (WSN) protocol using BA (bat algorithm)." IETE Journal of Research 61, no. 2 (2015): 170-179.

[30] Y. Bejerano, S. Han, and L. Li, "Fairness and load balancingin wireless lans using association control," IEEE Trans.Network., Vol. 15, no. 3, pp. 560-573, June 2007.

[31] S. Hong, et al.. "Estimating rain attenuation at 72 and84 $\mathrm{GHz}$ from raindrop size distribution measurements inAlbuquerque, NM, USA.” IEEE Geosci. Remote Sens. Lett.,Vol. 16, no. 8, pp. 1175-1179, 2019.

[32] Manvinder Sharma* and Harjinder Singh, "Substrate Integrated Waveguide Based Leaky Wave Antenna for High Frequency Applications and IoT”, International Journal of Sensors, Wireless Communications and Control (2019)
https://doi.org/10.2174/2210327909666190401210659.

[33] A. Nanzer, "A review of microwave wireless techniques for human presence detection and classification." IEEE Trans. Microwave Theory Tech., Vol. 65, pp. 1780-1794, 2017. 